Department of Otolaryngology, Aberdeen Royal Infirmary, UK P Jassar

M Jaramillo

D A Nunez

Correspondence to: Mr D A Nunez, Department of Otolaryngology, Ward 45, Aberdeen Royal Infirmary, Aberdeen AB25 2ZN, UK (email:

Dnunez1ORL@aol.com)

Submitted 28 October 1999 Accepted 10 February 2000

\title{
Base of tongue varices associated with portal hypertension
}

\author{
P Jassar, M Jaramillo, D A Nunez
}

\begin{abstract}
A symptomatic case of tongue base varices in a patient with portal hypertension secondary to liver cirrhosis is presented. There are no previously documented cases in the world literature. Oesophageal varices may not be the only source of expectorated blood in a patient with portal hypertension.

(Postgrad Med f 2000;76:576-577)
\end{abstract}

Keywords: portal hypertension; lingual; tongue; varicose vein

\section{Case report}

An 82 year old women with known portal hypertension secondary to cirrhosis of the liver was referred to the otolaryngology outpatient department with a two month history of daily haemoptysis and bloodstained pharyngeal secretions; this occurred mostly on early morning coughing. There was no history of weight loss, dysphagia, dysphonia, or throat pain. She had already been investigated for a pulmonary cause of the haemoptysis and none was found. In keeping with her history, liver function tests and the prothrombin time were abnormal. She also had a history of well controlled essential hypertension. Chest radiography showed cardiomegaly, but the jugular venous pressure was not raised and there was no other clinical manifestation of heart failure.

Indirect laryngoscopy revealed varicose vessels in the tongue base, mainly on the left side (see fig 1). These appeared friable and one area revealed a propensity to bleed on examination. The rest of the ear, nose, and throat examination was normal.

After perioperative cover with fresh frozen plasma, vitamin $K$, and tranexamic acid she

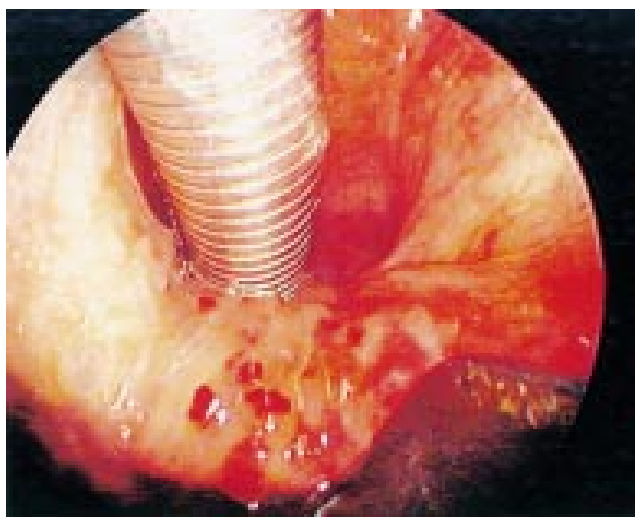

Figure 1 Tongue base varices. underwent ablation of the varicosities using a 15 watt continuous carbon dioxide laser under general anaesthesia (see fig 2). She had an uneventful recovery and has remained symptom free.

\section{Anatomy}

The dorsal lingual veins drain the tongue base through two or more tributaries. These course inferiorly, join together and form the lingual vein, which accompanies the lingual artery. These vessels pass between genioglossus and hyoglossus and the vein empties into the internal jugular vein just above the level of the greater cornu of the hyoid bone. ${ }^{1}$

\section{PORTOSYSTEMIC ANASTOMOSIS}

Because the portal system has no valves, portal hypertension results in shunting of blood through anastomotic communications with the systemic venous system. Recognised connections are ${ }^{2}$ :

(1) Lower oesophageal veins - the branches of the left gastric vein anastomose profusely with the azygous and hemiazygous veins. Increased shunting results in oesophageal varices within the mucosa of the lower third of the oesophagus.

(2) Periumbilical veins - veins contained in the falciform ligament anastomose with superior and inferior epigastric veins of the anterior abdominal wall. Excessive dilatation of these veins are evident as caput medusa.

(3) Haemorrhoids - the superior rectal vein anastomoses with the middle rectal vein which drains into the internal iliac vein. In addition the middle rectal veins anastomose with the inferior rectal veins which drain into the internal pudendal vein. Increased shunting results in internal and external haemorrhoids.

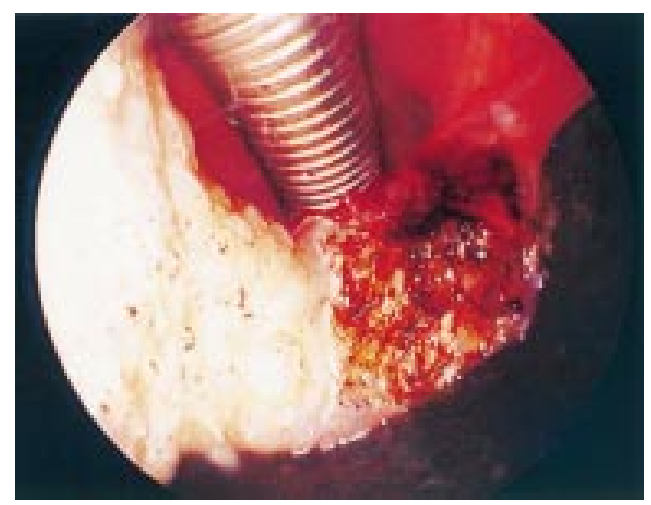

Figure 2 Tongue base varices after laser ablation. 
(4) Veins of Retzius - the veins of a secondary retroperitoneal structure may anastomose with the veins of the dorsal body wall, forming veins of Retzius.

Thus, there is no recognised anastomosis between lingual venous drainage and the portal circulation.

\section{Discussion}

A varicosity is a condition indicating an enlarged and tortuous vein. Previously described lingual varices referred to sublingual varices on the ventral surface of the tongue or floor of mouth. These were ascribed to the use of dentures, and vitamin C deficiency in an elderly population.

Burket associated the occurrence of lingual varices with cardiorespiratory disease, ${ }^{4}$ however this assumption was shown to be unsubstantiated in a double blind study by Kleinman. ${ }^{5}$

This represents the first reported case of dorsal tongue base varices in a patient with portal hypertension. We propose three expla- nations for this association. Firstly that the varices represent a spontaneous entity unrelated to systemic disease. Secondly, they are a manifestation of cardiopulmonary disease, an association endorsed by the known anatomic connection, but improbable given that there was no other clinical evidence of heart failure such as a raised jugular venous pressure. Lastly, that there is an, as yet, unrecognised anastomotic connection between lingual venous drainage and the portal circulation.

Tongue base varices should be considered in cases of blood expectoration and portal hypertension.

1 Gray H. Gray's anatomy. 15th Ed. New York: Bounty Books, 1978: 598.

2 April EW. Anatomy. 2nd Ed. National Medical Series. Baltimore: Williams and Wilkins, 1990: 229-30.

3 Colby RA, Kerr DA, Robinson HBG. Colour atlas of oral pathology. 2nd Ed. Philadelphia: JB Lippincott, 1961: 125.

4 Burket LW. Oral medicine. 4th Ed. Philadelphia: JB Lippincott, 1961: 146.

5 Kleinman HZ. Lingual varicosities. Oral Surgery, Oral Medicine, Oral Pathology 1967;23:546-8.

\title{
Cefuroxime induced lymphomatoid hypersensitivity reaction
}

\author{
S A M Saeed, M Bazza, M Zaman, K S Ryatt
}

Manor Hospital, Walsall, UK:

Department of Elderly Care

S A M Saeed

M Zaman

Department of Dermatology

M Bazza

K S Ryatt

Correspondence to:

Dr M Bazza, Department of Dermatology, Walsall Manor Hospital, Walsall, West Midlands WS2 9 PS, UK

Submitted 21 April 1999 Accepted 7 December 1999

\begin{abstract}
An 84 year old women developed erythematous blotchy erythema and purpuric rashes over the lower limbs three days after being started on intravenous cefuroxime for acute diverticulitis. A skin biopsy specimen showed a mixed infiltrate of lymphoid cells and eosinophils; many of the lymphocytes were large, pleomorphic, and showed a raised mitotic rate. Immunohistochemistry showed the infiltrate to be $T$ cell rich, with all the large cells being CD30 positive. Typical mycosis fungoides cells, marked epidermotropism, and Pautrier's abscesses were not seen. The rash disappeared 10 days after cessation of cefuroxime and the patient remained asymptomatic 15 months later. This apparent cutaneous $T$ cell lymphoma-like reaction is best described as lymphomatoid vascular reaction. The drug induced immune response with an atypical cutaneous lymphoid infiltrate mimics a cutaneous pseudolymphoma.

(Postgrad Med F 2000;76:577-579)
\end{abstract}

Keywords: cefuroxime; atypical cutaneous lymphomatoid infiltrate; cutaneous $\mathrm{T}$ cell lymphoma

\section{Case report}

An 84 year old women, with established diverticula disease, presented as an emergency with a short history of fever, acute abdominal pain, and diarrhoea. On examination she was found to be toxic, febrile, dehydrated, with a tachycardia of $110 / \mathrm{min}$ and blood pressure $80 / 40 \mathrm{~mm}$ $\mathrm{Hg}$. The left iliac fossa was tender. Haemoglobin, full biochemistry profile, including serum amylase, chest radiography, plain abdominal radiography, and an abdominal ultrasound scan were normal. Her white cell count was raised at $20.4 \times 10^{9} / 1$ with marked neutrophilia at $14.2 \times 10^{9} / 1$.

A provisional clinical diagnosis of acute diverticulitis with septic shock was made and she was started on intravenous (IV) fluids, IV metronidazole $500 \mathrm{mg}$ eight hourly, and IV cefuroxime $750 \mathrm{mg}$ three times a day in a sequential manner. Three days later and after five doses of IV cefuroxime, purpuric and erythematous macular rashes developed over the lower limbs. Cefuroxime was considered to be responsible and was discontinued; metronidazole was continued for another week. The rashes were treated with flucinolone acetonide $0.00625 \%$ cream. Further investigations at this stage showed normal immunoglobulins, antinuclear factor, antineutrophilic cytoplasmic antibodies, and autoantibody profile. A haematoxylin and eosin stained section of representative skin biopsy showed a mixed dermal infiltrate of lymphoid cells and eosinophils, marked red blood cell extravasation indicative of ongoing small vessel damage, minimal focal vacuolar interface 


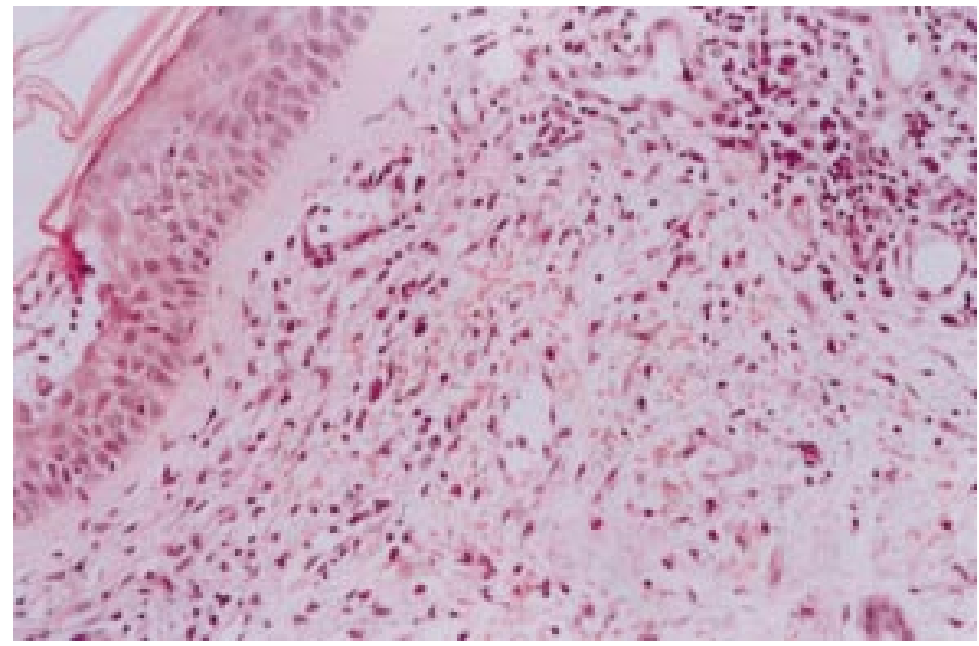

Figure 1 High power view, haematoxylin and eosin stain, demonstrating large, pleomorphic lymphoid cells with mitotic activity and lymphocytes in the background (original magnification $\times 40$ ).

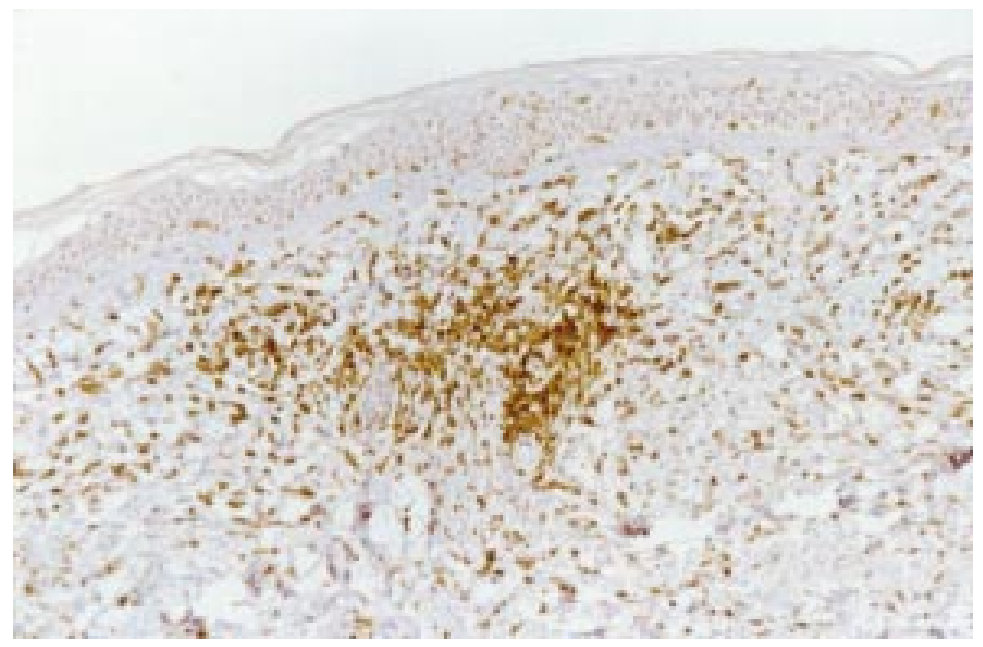

Figure 2 CD30 immunohistochemical stain demonstrating CD30 positive cells in the infiltrate (original magnification $\times 20$ ).

Table 1 Comparison between microscopical features of Mycosis fungoides and lymphomatoid vascular reaction

\begin{tabular}{|c|c|c|}
\hline Microscopical characteristic & Mycosis fungoides & $\begin{array}{l}\text { Lymphomatoid } \\
\text { vascular reaction }\end{array}$ \\
\hline Epidermotropisim & Marked and diffuse & Minimal and focal \\
\hline Pautrier's microabscesses & Usually present & Usually absent \\
\hline Eosinophils & Minimal or absent & Moderate \\
\hline Basilar vaculopathy & Usually absent & Usually present \\
\hline $\begin{array}{l}\text { Marked spongiosis, dermal } \\
\text { oedema, and keratinocyte } \\
\text { necrosis }\end{array}$ & $\begin{array}{l}\text { Usually absent papillary dermal } \\
\text { fibrosis rather than oedema is } \\
\text { the rule }\end{array}$ & Usually present \\
\hline Intraepidermal population of cells & Markedly atypical cytomorphology & $\begin{array}{l}\text { Mildly atypical } \\
\text { cytomorphology }\end{array}$ \\
\hline
\end{tabular}

change and some basement membrane hyalinisation, both within the papillary dermis of the inflamed skin and in the immediate vicinity. The lymphoid cells were predominantly lymphocytic, with many of these being large and polymorphic and showing hyperchromatic and irregular nuclei and mitoses (fig 1). Epidermotropism was only mild and focal and there were no Pautrier's abscesses. Immunohistochemistry showed the infiltrate to be $\mathrm{T}$ cell rich, with virtually all of the large cells being CD30 positive (fig 2). Direct immunofluorescence showed fine linear deposition of IgG along the dermoepidermal junction.
Pyrexia, diarrhoea, tachycardia, and hypotension improved rapidly with supportive measures and the rashes began to fade quickly and cleared within seven days. She was completely asymptomatic and clear of all rashes when reviewed more than 15 months after the initial episode.

\section{Discussion}

Cephalosporins are widely used for the treatment of septicaemia, pneumonia, meningitis, biliary and urinary tract infection, and peritonitis. Both the old and new third generations of cephalosporins are generally well tolerated at standard recommended dosage. ${ }^{1}$ The sequential cefuroxime regimen was chosen as it has been shown not only to be an effective treatment for severe infections but also easier to administer. ${ }^{2}$ The incidence of adverse effects is approximately $2.5 \%,{ }^{3}$ the most common being gastrointestinal-for example transient, mild to moderate nausea, diarrhoea, increase in serum transaminases and alkaline phosphatase, and very rarely Clostridium difficile induced pseudomembranous colitis. Other adverse reactions include central nervous system complaints - for example headache, dizziness, somnolence, confusion, hyperactivity, and reversible encephalopathy ${ }^{4}$ and transient haematological changes - for example leucopenia, thrombocytopenia and eosinophilia, serum sickness reaction, and renal failure. ${ }^{5}$ Cutaneous reactions are observed less frequently but urticaria, angio-oedema, erythema multiforme, exanthema, pruritus, pustular eruptions, fixed drug eruptions, glossitis, oral ulceration, and vaginitis have been described. ${ }^{6}$ HenochSchönlein purpura with systemic manifestations, including renal involvement ${ }^{7}$ and acute generalised exanthematic pustulosis ${ }^{8}$ have recently been reported. Phenytoin, ${ }^{9}$ carbamazepine, ${ }^{10}$ phenothiazine, ${ }^{11}$ angiotensin converting enzyme inhibitors, ${ }^{12} \beta$-blockers, ${ }^{13}$ antidepressants, ${ }^{14}$ and benzodiazepines ${ }^{15}$ have already been reported to cause atypical cutaneous lymphoid infiltrates, mimicking pseudolymphoma but cephalosporins, to our knowledge, have not been previously linked with this tissue response. Unlike the blotchy macular erythema and purpuric rashes as observed in our case, the more common mode of presentation was with solitary erythematous or purple nodules, a few infiltrated plaques or multiple infiltrative papules.${ }^{11-15}$ Some diagnostic confusion, both clinical and histological, occurs most commonly with mycosis fungoides and lymphomatoid vascular reaction (table1).

The precise mechanism of this drug induced lymphomatoid vascular reaction is unknown. However, the $\beta$-lactam ring of cephalosporins is well known to impart a degree of instability to the cephalosporin molecule; the ring can open up, conjugate with proteins, become a hapten and immunogenic, and thus induce a delayed type of hypersensitivity reaction. Indeed, moderate spongiosis, keratinocyte necrosis, papillary dermal oedema, the presence of angiocentric infiltrate of atypical lymphocytes, absent or minimal vessel wall damage, minimal 
and focal exocytosis of cells in the epidermis overlying the inflamed dermal papillae observed in this case are well recognised features of delayed type hypersensitivity reaction. Such a delayed type reaction with a cutaneous $\mathrm{T}$ cell lymphoma-like morphology has been described as lymphomatoid vascular reaction. ${ }^{16}$ Most of the large lymphocytic cells in the infiltrate stained CD30 positive. In the context of neoplasia, CD30 is positive in Reed-Sternberg cells of Hodgkin's disease, the cells of lymphomatoid papulosis and in anaplastic large cell lymphoma (Kil lymphoma). This has been shown to carry an excellent prognosis. ${ }^{10} 17$

The close temporal association of starting cefuroxime and the appearance of the rash, the cutaneous $\mathrm{T}$ cell lymphoma-like histology with more features of a lymphomatoid vascular reaction than mycosis fungoides and rapid resolution of rash on cessation of the suspected drug, all favour lymphomatoid hypersensitivity reaction to cefuroxime as the most likely diagnosis. This reaction pattern, not previously described with cephalosporins, appears to be a benign reaction, with there being no relapses for more than a year after cessation of the original offending drug. Our patient remains well and clear of her rash as well as showing no sign of developing any cutaneous or systemic lymphomatous pathology 15 months after her discharge.

We are grateful to Dr D Slater, Consultant Histopathologist, Rotherham General Hospital and Dr C Allen, Consultant Histopathologist, Walsall Manor Hospital for their advice on skin histology.
hopatholog
1 British Medical Association and Royal Pharmaceutical Society of Great Britain. British national formulary. Number 35. London: BMA and Royal Pharmaceutical Society of Great Britain, 1998.

2 Vogel F, Droszcz W, Vondra V, et al. Sequential therapy with cefuroxime followed by cefuroxime axetil in acute exacerbations of chronic bronchitis. F Antimicrob Chemother 1997;40: 863-71.

3 Lepper H, Estler C-J. Oral cephalosporins. Tolerability of oral cephalosporins. In: Moellering RC Jr, ed. Antibiotic chemotherapy. Basel: Karger, 1995;47:160-82.

4 Herishanu YO, Zlotnik M, Mostoslavsky $\mathrm{M}$, et al. Cefuroxime-induced encephalopathy. Neurology 1998;50: Cefuroxime.

5 Manley HJ, Bailie GR, Eisele G. Bilateral renal cortical necrosis associated with cefuroxime axetil. Clin Nephrol 1998;49:268-70

6 Litt JZ, Pawlak WA. Drug eruption reference manual. Partherion Publishing Group, 1997: 85-7.

7 Escudero A, Lucas E, Vidal JB, et al. Drug-related HenochSchönlein purpura. Allergol Immunopathol (Madr) 1996;24: $22-4$.

8 Eeckhout I, Noens L, Ongenae K, et al. Acute generalised exanthematic pustulosis: a case with a lymphoma-like presentation. Dermatology 1997;194:408-10.

9 Haris DW, Ostlere L, Buckley C, et al. Phenytoin-induced pseudolymphoma. A report of case and review of the literapseudolymphoma. A report of case and

10 Nathan DL, Belsito DV. Carbamazepine-induced pseudolymphoma with CD-30 positive cells. I Am Acad Dermatol 1998;38:806-9.

11 Rijlaarsdam U, Scheffer E, Meijer CJLM, et al. Cutaneous pseudo-T-cell lymphomas. A clinicopathologic study of 20 patients. Cancer 1992;69:717-24.

12 Furness PN, Goodfield MJ, MacLennan KA, et al. Severe cutaneous reactions to captopril and enalapril. Histological study and comparison with early mycosis fungoides. $\mathcal{F}$ Clin Pathol 1986;39:902-7.

13 Henderson CA, Shamy HK. Atenolol-induced pseudolymphoma. Clin Exp Dermatol 1990;15:119-120.

14 Crowson AN, Magro CM. Antidepressant therapy. A possible cause of atypical lymphoid hyperplasia. Arch Dermatol 1995;32:419-28.

15 Magro C, Crowson AN, Hatta T, et al. A 47 year old woman with spontaneously resolving scaling plaque. Fitzpatrick's fournal of Clinical Dermatology 1993;1:24-8.

16 Magro CM, Crowson AN. Drug-induced immune dysregulation as a cause of atypical cutaneous lymphoid infiltrates: a hypothesis. Hum Pathol 1996;27:125-33.

17 Russel-Jones R, Spittle MF. Management of cutaneous lymphoma. Ballieres Clin Haematol 1996;9:743-67.

\title{
Colonic carcinoma after ureterosigmoidostomy
}

\author{
A Huang, G A D McPherson
}

\begin{abstract}
Urinary carcinogens promote late malignant transformation of the colon after a ureterosigmoidostomy. An unusual case is presented where, despite the early removal of the latter and hence cessation of urine flow, a colonic carcinoma developed at the site of previous anastomosis. The importance of surveillance of all patients who have undergone this procedure to avoid an iatrogenic cancer is emphasised. (Postgrad Med J 2000;76:579-581)
\end{abstract}

Keywords: rhabdomyosarcoma; ureterosigmoidostomy; colonic carcinoma

Colonic carcinoma arising from the site of a functioning ureterosigmoidostomy anastomosis is a recognised late complication. If the anastomosis is subsequently taken down with no further urine flow into the bowel, the risk of neoplasia is reduced. We describe a rare case where a colonic carcinoma developed coincidentally at the site of a previous ureterosigmoidostomy after a long latent period.

\section{Case history}

A 41 year old man presented with rectal bleeding without bowel habit changes. At the age of 3 he underwent cystectomy with ureterosigmoidostomy formation for a rhabdomyosarcoma. Due to recurrent pyelonephritis the ureters were divided near the sigmoid colon and implanted in an ileal conduit seven years later. Two short segments of ureters were left attached to the colon.

Physical examination was normal and a barium enema revealed a lesion in the sigmoid colon. At laparotomy a circumferential cancer was found at the exact site of previous ureteric implantation (fig 1). Histological examination revealed a moderately differentiated adenocarcinoma with two short segments of residual
Submitt 1999

Accepted 20 January 2000 


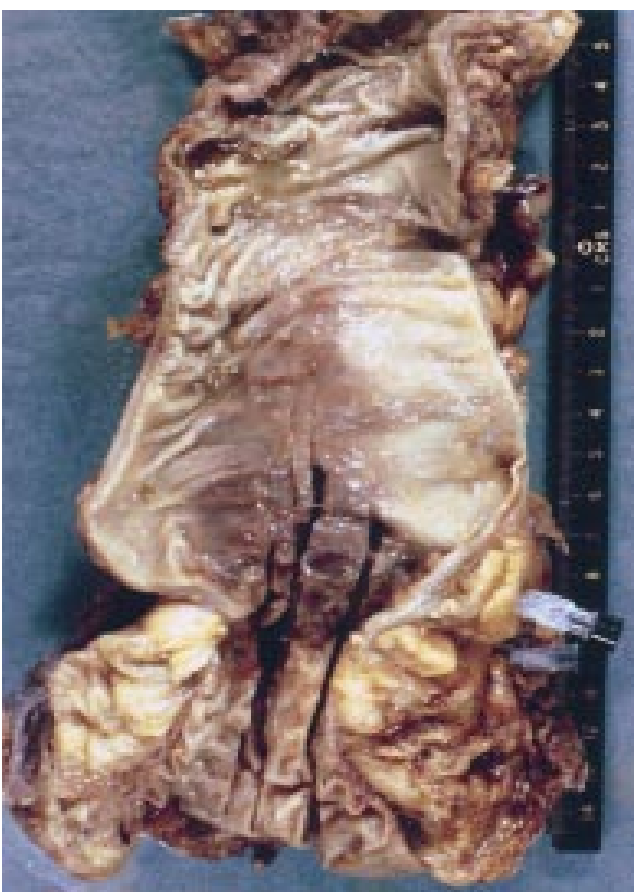

Figure 1 Resected specimen demonstrating sigmoid carcinoma with two short segments of ureters (markers).

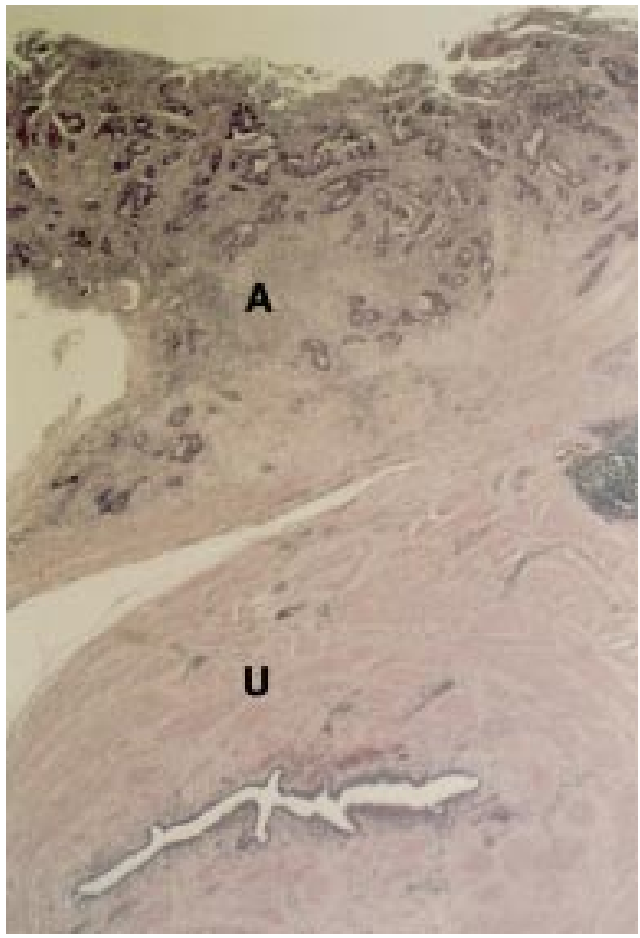

Figure 2 Photomicrograph of resected carcinoma $(A=$ adenocarcinoma; $U=$ ureter; haematoxylin and eosin $\times 30)$.

ureter (fig 2). Four of the 14 lymph nodes recovered contained metastatic deposits (Dukes C) and he received adjuvant chemotherapy with 5-fluorouracil and folinic acid.

\section{Discussion}

Colonic carcinoma developing at the site of ureteric implant was first described by Hammer in $1929 .{ }^{1}$ The incidence is 100 to 550 times that of the general population ${ }^{2}$ with an overall lifetime risk of $5 \%$; if the diversion is performed before the age of 25 years, the risk increases to 7000 -fold. ${ }^{3}$ The latency is between six to 50 years after the procedure ${ }^{4}$ with the mean time at 21 years; the median age at diagnosis is 33 years. ${ }^{5}$

Urine in direct contact with colonic epithelium plays a pivotal part in the initiation of carcinogenesis at the suture line. ${ }^{6}$ Stewart proposed that dietary nitrates excreted in urine come into the presence of high concentrations of secondary amines when diverted into the colon, with resultant bacterial activation of carcinogenic N-nitroso compounds. ${ }^{7}$ Constant faecal stream does not appear to be a prerequisite as carcinomas have been described arising from isolated colonic loops used as a neobladder. ${ }^{8}$ Other theories of carcinogenesis including surgical and mechanical trauma, excess concentrations of electrolytes, and chronic irritation resulting in malignant transformation have not been proved.

In the present case the ureterosigmoidostomy had been defunctioned many years previously and the subsequent development of a colonic carcinoma was likely to be a clinical coincidence. It could be argued that there was a causal link between the ureteric implantation and the bowel carcinoma, especially as the latter developed at such young age. However as there was no urine flow during this period this is unlikely.

Lifelong surveillance is recommended for all patients who undergo ureterosigmoidostomy. Starling et al suggested that annual colonoscopy with faecal occult blood test should be started soon after ureterosigmoidostomy, with subsequent alternative urinary diversion if recurrent polyps, cancer, or dysplasia were found. ${ }^{9}$ A more complex regimen of a faecal occult blood test every three months after two years, an excretory urogram yearly after five years, and sigmoidoscopy or colonoscopy every five years has also been proposed. ${ }^{2}$

Registries of patients are often undertaken in large centres ${ }^{7}$ but the long latency to cancer development with subsequent patient movement makes tracking of these patients difficult. ${ }^{9}$ Patients and their physicians should therefore be fully informed of the risks associated with this procedure so that appropriate surveillance could be arranged. Hospital specialists should have a high index of suspicion when a patient presents with a history of urinary diversion and hence the possibility of colonic malignancy. Failure to do so would prevent the early detection of an iatrogenic bowel cancer.

1 Hammer E. Cancer du colon sigmoide dix ans apres implantation des ureteres d'une vessie extrophiee. Fournal d'Urologie Medicale et Chirurgicale 1929;28:260-3.

2 Cipolla R, Garcia RL. Colonic polyps and adenocarcinoma complicating ureterosigmoidostomy: report of a case. $A m \mathcal{F}$ Gastroenterol 1984;79:453-7.

3 Eraklis AJ, Folkman MJ. Adenocarcinoma at the site of ureterosigmoidostomies for exstrophy of the bladder. $\mathcal{F}$ Pediatr Surg 1978;13:730-4.

4 Leadbetter GW Jr, Zickerman P, Pierce E. Ureterosigmoidostomy and carcinoma of the colon. F Urol 1979;121: $732-5$.

5 Sooriyaarachchi GS, Johnson RO, Carbone PP. Neoplasms

of the large bowel following ureterosigmoidostomy. Arch of the large bowel follow $1977 ; 112: 1174-7$.
Surg 
6 Daher N, Gautier R, Abourachid H, et al. Rat colonic arcinogenesis after ureterosigmoidostomy: pathogenesis

7 Stewart M. Urinary diversion and bowel cancer. Ann R Coll Surg Engl 1986;68:98-102.
8 Shaaban AA, Sheir KZ, el-Baz MA. Adenocarcinoma in an isolated rectosigmoid bladder: case report. $f$ Urol 1992;147: isolate

9 Starling JR, Uehling DT, Gilchrist KW. Value of colonoscopy after ureterosigmoidostomy. Surgery 1984;96:784-90.

\section{WEB SITE REVIEW}

\section{International Herpes Management Forum (www.IHMF.org)}

This large site has the most comprehensive collection imaginable of monographs, original papers and pictures on herpesvirus infections. Not just herpes simplex virus and varicella but cytomegalovirus, Epstein-Barr virus, human herpes virus 6,7 , and 8 are all exhaustively covered.

Complete monographs can be downloaded from the Library section or alternatively there are shorter management guidelines on such topics as herpesvirus infections in pregnancy and clinical implications of latency. There is also a whole section entitled Molecular Biology - all you ever wanted to know but were afraid to ask!

The site's welcome page implies that it will be useful to visitors ranging from specialists to patients but the format is heavily weighted in favour of health care professionals. Most patients would need a good medical dictionary at hand and the format is bland and rather uninviting for the casual visitor.

For specialists there is a journal club and there are regularly updated details of international virology meetings on another of the main sections. Also featured is a world map with links to herpesvirus organisations across the globe.

An Acrobat reader and PowerPoint are required to utilise large parts of the site but anyone with these facilities can download entire lecture presentations of high quality.

The site is sponsored by a pharmaceutical company but is not heavily promotional. Highly recommended.

T G STAMMERS Church Lane Practice, Merton Park, London SW19 3NY, UK 